Vol. 7, No. 1, 2019, pp. 8-15

DOI: https://doi.org/10.29210/129200

Contents lists available at Jurnal IICET

Jurnal Konseling dan Pendidikan

ISSN: 2337-6740 (Print) ISSN: 2337-6880 (Electronic)

Journal homepage: http://jurnal.konselingindonesia.com

\title{
Tracer study of the psychology faculty of UIN Raden Fatah Palembang in 2018: satisfaction of alumni and stakeholders on the implementation of Islamic psychology study programs
}

Tracer study fakultas psikologi UIN Raden Fatah Palembang tahun 2018: kepuasan alumni dan stakeholder terhadap penyelenggaraan program studi psikologi Islam

\author{
Listya Istiningtyas ${ }^{1}$, Lukmawati Lukmawati $^{2}$ \\ ${ }^{12}$ UIN Raden Fatah Palembang, Indonesia
}

\section{Article Info \\ Article history:}

Received November $19^{\text {th }}, 2019$

Revised April $23^{\text {th }}, 2019$

Accepted May $23^{\text {th }}, 2019$

\section{Keyword:}

Tracer study

Satisfaction

Alumni

Stakeholders

Quality of service

\begin{abstract}
As a Study Program in the new Faculty, it has produced over 400 alumni, but for ten years there has never been test the alumni side or from the stakeholder side (end user), so it is necessary to conduct research to test the satisfaction level of alumni and stakeholders. The research method used is a mixedmethod with concurrent design, which uses quantitative and qualitative research. From the results of the study we can conclude it that the alumni feel quite satisfied with an average score of 3 on the three indicators; teaching and learning process, administration process and provision of facilities in Islamic Psychology Study Program, Faculty of Psychology. Therefore, it still needs to be improved in a lecture, computer and internet facilities. Islamic Psychology Study Program Faculty of Psychology has fulfilled most of the expectations of stakeholders and alumni. The advice given by stakeholders to the Faculty of Psychology to be more advance relates to improve physical facilities, human resources, services and competitiveness of graduates.
\end{abstract}

C 2019 The Authors. Published by Indonesian Institute for Counseling,

Education and Therapy (IICET). This is an open access article under the CC BY license (https://creativecommons.org/licenses/by/4.0/)

\section{Corresponding Author:}

Lukmawati Lukmawati,

Email: lukmawati_uin@radenfatah.ac.id

\section{Pendahuluan}

Pendidikan bermutu adalah pendidikan yang mampu melakukan proses pematangan kualitas peserta didik yang dikembangkan dengan cara membebaskan peserta didik dari ketidaktahuan, ketidakmampuan, ketidakberdayaan, ketidakbenaran, ketidakjujuran, dan dari buruknya akhlak dan keimanan (Mulyasa, 2012). Pendidikan tinggi yang bermutu harus mampu mengantarkan output lulusan yang memiliki seperangkat pengetahuan, skill, berkarakter atau memiliki kematangan secara intelektual, emosional dan spiritual serta mampu menguasai dan diterima dalam persaingan dunia kerja yang semakin kompetitif (Azis, 2016; Mitrofanova, Simonova, \& Tarasenko, 2020).

Perguruan tinggi harus memberikan pelayanan yang memiliki ciri khusus yang tidak bisa disamakan dengan lembaga jasa lain diluar perguruan tinggi. Misalnya pelayanan yang diberikan kepada mahasiswa dan alumni terikat dengan peraturan dari perguruan tinggi dan DIKTI. Bentuk pelayan yang diterima oleh mahasiswa dan alumni dalam perguruan tinggi mencakup pelayanan dalam kegiatan akademik, kemahasiswaan dan administrasi (Kearney, Naifeh, Hammer, \& Cain, 2019). Pelayanan yang prima akan berdampak pada peningkatan citra perguruan tinggi dan sebaliknya pelayanan yang buruk akan menurunkan citra perguruan tinggi itu sendiri. Citra terbentuk dari kesan, impresi, dan perasaan berdasarkan pengalaman tentang kualitas yang dialami oleh seseorang terhadap penyedia jasa tersebut (Kotler, P., \& Keller, 2006; Liu \& Ni, 2020). Menurut Ruben (1999), terdapat lima hal pokok yang harus diperhatikan oleh pihak manajemen perguruan tinggi agar terjaga mutu pendidikannya, dia menyebutnya sebagai dashboard 
indicator, yaitu: 1). teaching/learning, 2). service/outreach, 3). schollarship/research, 4). workplace satisfaction, dan 5). financial. Dalam pengelolaan perguruan tinggi, terjadi pergeseran paradigma tentang pengelolaan perguruan tinggi selayaknya mengelola perusahaan. Hal ini disebabkan karena sekarang sumber pendanaan yang utama bagi perguruan tinggi berasal dari mahasiswa, jadi sudah selayaknya pihak manajemen selalu berorientasi diri pada terciptanya kepuasan mahasiswa dan alumninya sebagai output atau produk yang dapat dirasakan langsung oleh stakeholder, yaitu dunia kerja (enduser), orangtua dan masyarakat (Dickson, Harvey, \& Blackwood, 2019; Pham, Limbu, Bui, Nguyen, \& Pham, 2019).

Keberhasilan suatu perguruan tinggi sangat ditentukan oleh mutu pelayanan yang diberikan, dimana pelayanan yang bermutu dapat diidentifikasi melalui kepuasan pelanggan, dalam hal ini adalah mahasiswa (Rolbina, Novikova, Sharafutdinova, Martynova, \& Akhmetshin, 2020; Vesloguzova, Petrik, Salikhov, \& Bunakov, 2020). Keadaan persaingan yang kompetitif antar perguruan tinggi menuntut lembaga pendidikan harus memperhatikan mutu pendidikan dan kelembagaan sehingga mampu serta unggul dalam persaingan tersebut. Perguruan tinggi harus melakukan langkah antisipasi guna menghadapi persaingan yang semakin kompetitif serta bertanggung jawab untuk menggali dan meningkatkan segala aspek pelayanan yang dimiliki. Cravens (Handayani \& Keban, 2004) menyatakan bahwa "untuk mencapai tingkat kepuasan yang tinggi diperlukan adanya pemahaman tentang apa yang diinginkan oleh konsumen, dengan mengembangkan komitmen setiap orang yang ada dalam lembaga untuk memenuhi kebutuhan konsumen."

Sebagai program studi di Fakultas yang baru, sangat diperlukan perbaikan, evaluasi dan peningkatan pelayanan baik secara fisik maupun pelayanan nonfisik. Fasilitas, sarana prasarana dan kelengkapankelengkapan akademik lainnya juga masih membutuhkan perbaikan. Salah satu umpan balik yang dibutuhkan oleh pengelola program adalah tingkat kepuasan mahasiswa yang saat ini sudah menjadi alumni terhadap penyelenggaraan program tersebut (Dickson et al., 2019). Dengan mengetahui tingkat kepuasan alumni, pengelola program dapat membuat kebijakan-kebijakan, tindakan-tindakan dan sarana serta fasilitas pendukung yang dapat meningkatkan penyelenggaraan Program Studi Psikologi Islam tersebut di masa mendatang. Sebagai Prodi yang sekarang telah menghasilkan lulusan, maka perlu diadakan penelitian untuk melakukan evaluasi terhadap tingkat kepuasan alumninya, hal ini dimaksudkan agar Fakultas mengetahui sejauh mana kualitas pelayanan yang telah diberikan kepada para alumni (saat menjadi mahasiswa) agar dapat melakukan peningkatan penyelenggaraan program studi khususnya pada kualitas pelayanan dan pembelajaran.

\section{Penyelenggaraan program studi}

Salah satu penyelenggaraan program studi yang dilakukan oleh suatu instansi/lembaga pendidikan adalah pelayanan. Oleh sebab itu, dalam penelitian kualitas pelayanan menjadi aspek yang paling penting untuk diukur. Dengan demikian kualitas pelayanan adalah salah satu aspek yang akan digunakan dalam penyelenggaraan pendidikan di program studi. Dengan demikian, peneliti secara detail menjelaskan tentang kualitas pelayanan karena akan akan diukur secara detail.

Pelayanan didefinisikan sebagai kegiatan ekonomi yang menciptakan dan memberikan manfaat bagi pelanggan pada waktu dan tempat tertentu, sebagai hasil dan tindakan mewujudkan perubahan yang diinginkan dalam diri atau atas nama penerima jasa tersebut (C. H., 2002). Pengertian pelayanan menurut Kotler (2004), yaitu setiap tindakan atau kegiatan yang dapat ditawarkan oleh satu pihak kepada pihak lain pada dasarnya tidak berwujud dan tidak mengakibatkan kepemilikan apapun.

Parasuraman, Zeithamel, \& L.L. (1994) mengatakan bahwa dalam jasa memiliki lima dimensi kualitas pelayanan yaitu; tangible (bukti fisik), reliable (kehandalan), responsiveness (daya tanggap), assurance (jaminan) dan emphaty (empati).

\section{Kepuasan alumni dan stakeholder}

Kata kepuasan atau satisfaction berasal dari bahasa latin "satis" (artinya cukup baik, memadai) dan "facio" (melakukan atau membuat). Secara sederhana kepuasan dapat diartikan sebagai upaya pemenuhan sesuatu atau membuat sesuatu memadai. Konsep kepuasan pelanggan masih bersifat abstrak, meski demikian kepuasan pelanggan menjadi konsep sentral dalam teori dan praktik pemasaran, serta merupakan salah satu tujuan esensial bagi aktivitas bisnis (Tjiptono \& Diana, 2003).

Kepuasan adalah tingkat perasaan seseorang setelah membuat perbandingan antara kenyataan yang ia rasakan dengan harapannya (Sukanti, 2009). Pemikiran konsumen ini juga dikatakan oleh (Kotler, 2004) yang mendefinisikan kepuasan sebagai perasaan senang atau kecewa seseorang yang dialami setelah membandingkan antara persepsi kinerja atau hasil suatu produk dengan harapan-harapannya. Jika kinerja berada dibawah harapan, maka pengguna jasa tidak puas. Sedangkan jika kinerja memenuhi harapan, maka 
pengguna jasa layanan puas. Definisi kepuasan mengacu pada persetujuan seseorang atau kekecewaan ketika membandingkan pendapat pribadi layanan mereka diterima dengan harapan asli layanan mereka (Kotler, P., \& Keller, 2006). Dengan demikian kepuasan konsumen dapat dipahami sebagai keseluruhan sikap yang timbul setelah membeli atau menggunakan sebuah produk atau jasa.

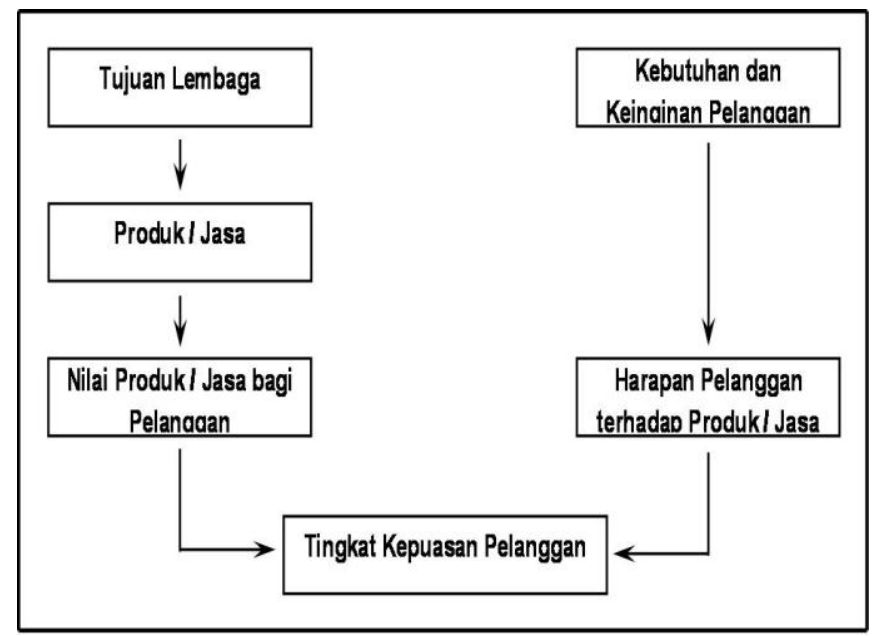

Gambar 1. Konsep Kepuasan Pelanggan

Stakeholder terdiri dari dua buah kata, yaitu "stake"dan "holder". Secara umum, kata "stake" dapat diterjemahkan sebagai "kepentingan", sedangkan kata "holder" dapat diartikan sebagai "pemegang" (Mashoufi, Ayatollahi, \& Khorasani-Zavareh, 2019). Jadi stakeholder artinya adalah pemegang kepentingan (Estaswara, 2010). Dapat dipahami bahwa stakeholder dapat didefinisikan sebagai berikut "individu atau organisasi atau kelompok baik profit maupun non profit yang memiliki kepentingan dengan perusahaan sehingga dapat mempengaruhi atau dipengaruhi oleh pencapaian tujuan perusahaan" (Zhang \& Smith, 2019). Dengan demikian dapat dipahami bahwa stakeholder adalah pemegang keputusan yang memiliki kepentingan dalam keberlangsungan sebuah organisasi, baik sebagai individu/kelompok yang mempengaruhi maupun dipengaruhi dalam pencapaian tujuan sebuah organisasi.

\section{Metode}

Metode yang digunakan dalam penelitian ini adalah mixed methods. Penelitian ini merupakan suatu langkah penelitian dengan menggabungkan dua bentuk penelitian yang telah ada sebelumnya yaitu penelitian kuantitatif dan penelitian kualitatif. Menurut Creswell (2011), penelitian campuran merupakan pendekatan penelitian yang mengkombinasikan antara penelitian kualitatif dengan penelitian kuantitatif. Sejalan hal itu, Sugiyono (2010) menyatakan bahwa metode penelitian kombinasi (mixed methods) adalah suatu metode penelitian yang mengkombinasikan atau menggabungkan antara metode kuantitatif dengan metode kualitatif untuk digunakan secara bersama-sama dalam suatu kegiatan penelitian, sehingga diperoleh data yang lebih komprehensif, valid, reliabel dan obyektif. Berdasarkan bagan di atas, dapat diketahui bahwa dalam prosesnya penelitian ini dilakukan dengan teknik concurrent design artinya peneliti dalam waktu bersamaan mengumpulkan data kuantitatif dan data kualitatif yaitu menyebar kuesioner sekaligus melakukan FGD (focus Group Discussion) kepada beberapa alumni guna mendapatkan data yang lebih komprehensif.

Instrument yang digunakan dalam penelitian yaitu kuesionair. Populasi dalam penelitian ini adalah seluruh alumni Prodi Psikologi Islam Fakultas Psikologi UIN Raden Fatah Palembang yang berjumlah 410 orang. Dalam penentuan jumlah sampel peneliti menggunakan penentuan jumlah sampel Isaac dan Michael dengan taraf kesalahan $10 \%$ yaitu 165 orang (Sugiyono, 2010). Namun, karena keterbatasan waktu yang telah ditentukan, kuesioner yang kembali hanya 154 kuesioner. Tempat penelitian yang digunakan dalam penelitian ini adalah Palembang dan wilayah Sumsel karena sebagian besar responden berasal dari wilayah tersebut. 


\section{Hasil dan Pembahasan}

Pada indikator kepuasan alumni yang pertama yaitu kepuasan alumni terhadap kualitas proses belajar mengajar di lingkungan Program Studi Psikologi Islam Fakultas Psikologi UIN Raden Fatah Palembang diperoleh berkisar pada skor 3. Hal ini menunjukkan mahasiswa sudah merasa cukup puas dengan proses belajar mengajar yang ada. Indikator yang membutuhkan perhatian yaitu pada kategori fasilitas perkuliahan, dimana rata-rata subjek menjawab kurang puas. Secara keseluruhan, kepuasan alumni Prodi Psikologi Islam UIN Raden Fatah Palembang pada indikator belajar mengajar relatif tinggi.

Indikator kepuasan alumni yang kedua adalah kepuasaan alumni terkait dengan proses administrasi saat menjadi mahasiswa dan setelah menjadi mahasiswa. Proses administrasi sangat menentukan apakah sebuah instansi atau lembaga teroganisir atau tidak. Berdasarkan hasil penelitian, ditemukan bahwa kepuasan alumni terhadap proses administrasi berkisar pada skor 3. Hal ini menunjukkan alumni sudah merasa cukup puas dengan proses administrasi yang ada. Secara keseluruhan, kepuasan alumni Prodi Psikologi Islam UIN Raden Fatah Palembang pada indikator administrasi relatif tinggi.

Indikator kepuasan alumni yang ketiga adalah kepuasaan alumni terkait penyediaan fasilitas bagi alumni (termasuk saat menjadi mahasiswa). Fasilitas (sarana-prasarana) memegang peranan penting dalam organisasi/lembaga/ instansi karena proses belajar mengajar dan proses administrasi sangat ditunjang oleh unsur fasilitas. Dengan kata lain, berjalan atau tidaknya sebuah lembaga atau instasi dapat dilihat dari tersedia atau tidaknya fasilitas yang mendukung, semakin lengkap fasilitas maka sebaik lancar proses belajar mengajar dan administrasi. Berdasarkan hasil penelitian, ditemukan bahwa kepuasan mahasiswa terhadap penyediaan fasilitas mahasiswa berkisar pada skor 3. Hal ini menunjukkan alumni (termasuk saat menjadi mahasiswa) merasa cukup puas dengan penyediaan fasilitas yang ada. Namun pada indikator ini terdapat cukup banyak prioritas perbaikan yang perlu dibenahi seperti pada fasilitas fisik, komputer dan internet. Secara keseluruhan, kepuasan alumni Prodi Psikologi Islam UIN Raden Fatah Palembang pada indikator fasilitas relatif tinggi.

Penilaian stakeholder terhadap kualitas alumni prodi Psikologi Islam secara umum baik (skor 4). Namun pada indikator tertentu penilaian stakeholder terhadap alumni Prodi Psikologi Islam, cenderung cukup baik yaitu indikator Jiwa kepemimpinan, kemampuan berkomunikasi dalam bahasa asing dan visioner. Selanjutnya, kepuasaan stakeholder dari perusahaan/instansi/lembaga tempat alumni bekerja yang merupakan perusahaan perwakilan atau cabang, menunjukan berbagai kategori yaitu; puas mencapai $58.70 \%$ ( 27 responden), sangat puas $23.11 \%$ (11 responden), cukup puas mencapai $17.39 \%$ ( 8 responden).

Tabel 1. Kepuasaan Stakeholder terhadap Alumni Psikologi Islam

\begin{tabular}{|c|c|c|}
\hline \multicolumn{2}{|c|}{ Kepuasan stakeholder } & Persen \\
\hline Sangat tidak puas & 0 & 0 \\
\hline Kurang puas & 0 & 0 \\
\hline Cukup puas & 8 & $17.39 \%$ \\
\hline Puas & 27 & $58.70 \%$ \\
\hline Sangat puas & 11 & $23.91 \%$ \\
\hline Jumlah & 46 & $100.00 \%$ \\
\hline
\end{tabular}

Kepuasan alumni terkait proses belajar mengajar yang ada di lingkungan Program Studi Psikologi Islam Fakultas Psikologi UIN Raden Fatah Palembang, berkisar pada skor 3. Hal ini menunjukkan mahasiswa sudah merasa cukup puas dengan proses belajar mengajaryang ada. Sebagaimana diketahui bahwa mean empiris variabel kepuasan alumni indikator proses belajar mengajar diperoleh subjek lebih besar dibandingkan dengan mean hipotetisnya. Artinya Kepuasan alumni Prodi Psikologi Islam UIN Raden Fatah Palembang pada indikator belajar mengajar relatif tinggi.

Hal ini sejalan dengan hasil FGD bahwa alumni merasa puas dengan proses belajar mengajar yang telah ditetapkan oleh prodi. Kepuasan tersebut dinilai alumni berdasar pada kompetensi dosen yang sesuai dengan kualifikasi pendidikan psikologi, profesionalitas dosen, kurikulum yang semakin sesuai dengan kebutuhan dunia kerja, kemudahan konsultasi dan komunikasi antara dosen dan mahasiswa dan lain-lain. Sebagaimana dikatakan (Parasuraman et al., 1994) bahwa menerapkan dimensi daya tanggap dapat tercermin dari keinginan atau kesiapan karyawan dan dosen dalam memberikan pelayanan setiap saat, antara lain 
bimbingan dosen terhadap mahasiswa yang mengalami kesulitan belajar, kebijakan dan upaya lembaga dalam mengikuti perkembangan jaman dan IPTEK, kesediaan pimpinan lembaga dalam menanggapi keluhan-keluhan mahasiswa dan berupaya untuk menyelenggarakan pelayanan yang lebih baik.

Selanjutnya, indikator kepuasan alumniyang kedua adalah kepuasaan alumni terkait dengan proses administrasi saat menjadi mahasiswa dan setelah menjadi mahasiswa. Proses administrasi merupakan hal yang sangat penting dalam kegiatan pelayanan akademik. Proses administrasi sangat menentukan apakah sebuah instansi atau lembaga teroganisir atau tidak. Dengan kata lain, bagus tidaknya sebuah lembaga atau instansi dapat dilihat dari rapi atau tidaknya, teroganisir atau tidaknya sebuah administrasi. Berdasarkan hasil penelitian, menunjukkan bahwa kepuasan alumni terhadap proses administrasi berkisar pada skor 3 . Hal ini menunjukkan alumni sudah merasa cukup puas dengan proses administrasi yang ada. Hasilmean empiris variabel kepuasan alumni yang diperoleh subjek lebih besar dibandingkan dengan mean hipotetisnya. Artinya kepuasan alumni Prodi Psikologi Islam UIN Raden Fatah Palembang pada indikator administrasi relatif tinggi. Dengan hasil kategori yang didapatkan bahwa skala kepuasan alumni pada indikator administrasi berada di taraf sedang dengan frekuensi sebanyak yaitu 104 alumni dengan persentasi 67,54 \%. Hal ini sejalan dengan hasil FGD bahwa alumni merasa puas dengan proses administrasi yang ada. Kepuasan tersebut dinilai alumni berdasarkan pada serangkaian proses daftar ulang yang mudah, pendaftaran beasiswa, seminar proposal, ujian komprehensif dan ujian munaqosyah, walaupun saat ini sistem belum terstandar online.Hal ini sesuai dengan apa yang dikatakan (Parasuraman et al., 1994) bahwa menerapkan dimensi keyakinan dapat terlihat dengan adanya kepastian bahwa para staf lembaga pendidikan tersebut memiliki keterampilan dan moralitas yang baik serta dapat dipercaya. Misalnya para dosen ahli dalam bidangnya dan bekerja secara profesional, staf administrasi terampil dan ramah dalam memberikan pelayanan. Selain itu, empati dapat ditunjukkan dengan adanya perhatian terhadap keamanan, ketenangan, dan kenyamanan mahasiswa dalam belajar, penyaluran lulusan ke perusahaan,dan lain-lain.

Indikator kepuasan alumni yang ketiga adalah kepuasaan alumni terkait penyediaan fasilitas bagi alumni (termasuk saat menjadi mahasiswa). Penyediaan fasilitas tidak kalah pentingnya dengan indikator pertama (proses belajar-mengajar) dan kedua (proses administrasi). Mengingat berjalannya indikator pertama dan kedua harus difasilitasi oleh indikator ketiga. Fasilitas (sarana-prasarana) memegang peranan penting dalam organisasi/lembaga/instansi. Oleh sebab itu, proses belajar mengajar dan proses administrasi sangat ditunjang oleh unsur fasilitas. Terkhusus fasilitas inti misalnya, tersedia gedung, ruangan khusus yang representatif, komputer, kursi, meja, dan lain-lain. Dengan kata lain, berjalan atau tidaknya sebuah lembaga atau instansi dapat dilihat dari tersedia atau tidaknya fasilitas yang mendukung, semakin lengkap fasilitas maka sebaik lancar proses belajar mengajar dan administrasi. Berdasarkan hasil penelitian, kepuasan alumni (termasuk saat menjadi mahasiswa) terhadap penyediaan fasilitas mahasiswa berkisar pada skor 3. Hal ini menunjukkan alumni merasa cukup puas dengan penyediaan fasilitas mahasiswa yang ada. Namun pada indikator ini terdapat cukup banyak prioritas perbaikan yang perlu dibenahi seperti pada fasilitas komputer. Hasil mean empiris variabel kepuasan alumni yang diperoleh subjek lebih besar dibandingkan dengan mean hipotetisnya. Artinya kepuasan alumni Prodi Psikologi Islam UIN Raden Fatah Palembang pada indikator fasilitas relatif tinggi. Dengan kategori hasil bahwa skala kepuasan alumni pada indikator penyediaan fasilitas berada di taraf sedang dengan frekuensi sebanyak yaitu 102 alumni dengan persentasi 66,23\%.

Hal ini sesuai dengan hasil FGD yang menunjukkan bahwa penyediaan fasilitas (sarana prasarana) sangat minim. Dimulai dari fasilitas komputer, gedung/ruangan, ektrakulikuler, internet/wifi yang terbatas, dan lain-lain. Hal sejalan dengan hasil observasi peneliti juga bahwa fakultas psikologi belum memiliki gedung secara independen, ruang kelas, laboratarium yang tidak standar. Hal ini sesuai dengan apa yang dikatakan (Parasuraman et al., 1994) bahwa menerapkan dimensi berwujud berkaitan dengan segala sesuatu yang bernuansa fisik dari pelayanan, termasuk fasilitas fisik (sarana dan prasarana) lembaga dan personalia (dosen dan karyawan). Contoh dari dimensi ini antara lain bangunan fisik beserta segala pelengkapan perkuliahan seperti meja, kursi, papan tulis, peralatan laboratorium, perpustakaan, kantin, lapangan olah raga, lapangan parker kendaraan bermotor, taman, dan lain-lain.

Pada organisasi jasa termasuk pendidikan tinggi, produk jasa diterima olehpelanggan pada saat terjadi interaksi antara dosen dengan penerima jasa (mahasiswa), sehingga kompetensi dosen dan kualitas proses pembelajaran dalam bekerja sangat menentukan kualitas produk jasa yang dihasilkan (Frizsimmons \& Mona, 2001). Perubahan paradigma manajemen perguruan tinggi yaitu bersifat melayani, harus diimbangi dengan perubahan budaya kerja dosen dan karyawan (employee) yang juga berorientasi pada pelayanan. Jika dahulu hubungan antara dosen dan mahasiswa bersifat patron and client, maka kini budayanya harus diubah menjadi hubungan kemitraan. Berdasarkan Kuesioner kepuasan mahasiswa hasil penelitian 
menunjukkan bahwa kompetensi dosen dan bimbingan akademik dinilai memuaskan, Penyelesaian masalah oleh dosen dan konsultasi mahasiswa juga dinilai cukup memuaskan.

Pelayanan yang prima akan berdampak pada peningkatan citra perguruan tinggi dan sebaliknya pelayanan yang buruk akan menurunkan citra perguruan tinggi itu sendiri. Citra terbentuk dari kesan, impresi, dan perasaan berdasarkan pengalaman tentang kualitas yang dialami oleh seseorang terhadap penyedia jasa tersebut (Kotler, P., \& Keller, 2006). Meskipun disebut produk parsial, lulusan perguruan tinggi adalah produk yang sangat penting, yang bersifat generatif dan aplikatif. Generatif bermakna bahwa melalui lulusanlah jasa-jasa perguruan tinggi disebarluaskan dan dikembangkan. Sedangkan dikatakan "aplikatif" karena lulusan akan mengaplikasikan jasa-jasa perguruan tinggi yang telah diterimanya dalam dunia kerja (Panji, 2007). Berdasarkan Kuesioner kepuasan alumni hasil penelitian menunjukkan bahwa pelaksanaan dan kesesuaian kurikulum dinilai baik oleh sebagian besar alumni, begitupun dalam indikator peningkatan daya saing.

Prodi Psikologi Islam sebagai salah satu lembaga pendidikan tinggi, harus menerapkan konsep mengutamakan kepuasan mahasiswa sebagai pelanggan dengan memberikan pelayanan terbaik. Beberapa bidang pelayanan yang harus di kembangkan secara berkelanjutan meliputi kurikulum program studi, proses pembalajaran, sumber daya manusia (dosen dan karyawan), sarana dan prasarana. Terciptanya kepuasan mahasiswa melalui proses belajar mengajar dapat merupakan promosi tanpa mengeluarkan biaya karena mahasiswa yang merasa puas tersebut akan menyampaikan kepada rekan-rekannya yang lain untuk memilih tempat kuliah di Prodi Psikologi Islam. Dengan kata lain mahasiswa tersebut membentuk rekomendasi dari mulut kemulut (word of mouth) yang dapat menguntungkan lembaga (Tjiptono, 2008). Harapan bahwa pendidikan tinggi harus mampu memberikan pelayanan terbaik bagi peserta didik telah disampaikan secara luas oleh (Sadat, 2000). Untuk mencapai itu, kesesuaian antara keinginan atau persepsi konsumen (costumer voice) dan keinginan organisasi pengelola/perguruan tinggi (company voice) syarat penting dalam keberhasilan proses pendidikan (Muafi \& Siswanti, 2007). Dapat disimpulkan berdasarkan Kuesioner kepuasan mahasiswa hasil penelitian menunjukkan bahwa mahasiswa sudah cukup puas dengan pelayanan yang diberikan Prodi Psikologi Islam Fakultas Psikologi. Prodi Psikologi Islam Fakultas Psikologi sudah memenuhi sebagian besar dari harapan mahasiswa dan alumni. Hanya saja dalam indikator fasilitas perkuliahan masih perlu dibenahi dan ditingkatkan guna memenuhi harapan mahasiswa dan alumni menjadi kenyataan.

Pengembangan akademik prodi Psikologi Islam menjadi Fakultas Psikologi tentu saja terdapat berbagai kemungkinan keberhasilan dan kegagalan dalam menjalankan programnya, baik secara internal maupun eksternal. Faktor internal merupakan kekuatan yang berpotensi dapat menunjang keberhasilan dalam pengembangan, serta kelemahan yang mungkin menjadi kendala dalam pelaksanaan pengembangan. Sedangkan faktor eksternal merupakan tantangan sebagai konsekuensi dari perkembangan masyarakat yang dinamis, dan peluang yang merupakan celah-celah harapan memungkinkan pengembangan prodi Psikologi Islam. Rencana Strategis disusun sebagai pedoman bagi penyelenggaraan dan pengelolaan Fakultas Psikologi dalam jangka jangka pendek (tiga tahun kedepan), jangka menengah (lima tahun kedepan) dan jangka panjang (sepuluh tahun kedepan) (Psikologi, 2017a). Berdasarkan rencana strategis yang telah dibuat, diharapkan wujud nyata dari penyelenggaraan dan pengelolaan Fakultas Psikologi yang bermutu dan berkualitas dengan bersandarkan pada sisi keilmuan yang berwawasan Nasional dan berkarakter Islami benar-benar terintegrasi dalam bentuk lulusan yang berguna dan bisa mendarma baktikan kompetensinya demi membangun masa depan bangsa dan peradaban manusia yang lebih baik (Psikologi, 2017b).

Keterbatasan atau kelemahan dalam penelitian ini terletak pada hal-hal sebagai berikut: pertama, pengumpulan data melalui kegiatan FGD hanya dapat dilakukan pada alumni sedangkan pada stakeholder tidak dilakukan karena keterbatasan waktu pelaksanaan penelitian. Kedua, kurang luasnya jangkauan responden alumni mengingat banyaknya alumni yang tersebar didaerah luar Palembang. Ketiga penggunaan disain mix-methode kurang optimal disebabkan oleh waktu pelaksanaan penelitian yang terbatas. Keempat, alat ukur yang digunakan penyebaran dan pengisiannya masih manual, akan lebih optimal jika dilakukan dengan aplikasi program komputer. Kelima, responden stakeholder penelitian hanya fokus pada user (pengguna lulusan) saja, diperlukan penelitian lanjutan mengenai stakeholder yang lebih luas.

\section{Kesimpulan}

Berdasarkan hasil penelitian dapat disimpulkan bahwa kuesioner kepuasan alumni menunjukkan alumni merasa cukup puas dengan rata-rata skor 3 pada ketiga indikator yaitu; proses belajar mengajar, proses administrasi dan penyediaan fasilitas di Prodi Psikologi Islam Fakultas Psikologi. Oleh sebab itu, masih 
perlu ditingkatkan lagi terkhusus pada fasilitas perkuliahan, komputer dan internet. Prodi Psikologi Islam Fakultas Psikologi telah memenuhi sebagian besar dari harapan alumni dan stakeholder. Masukan yang diberikan alumni dan stakeholder untuk Fakultas Psikologi agar lebih maju dimasa mendatang berhubungan dengan peningkatan fasilitas fisik, peningkatan SDM, peningkatan pelayanan dan peningkatan daya saing lulusan.

\section{Referensi}

Azis, S. (2016). Manajemen Mutu Perguruan Tinggi: Koreksi dan Implementasi. Yogyakarta: Gava Media.

C. H., L. (2002). Service Marketing. Second Edition, Englewood Cliffs. New Jersey: Prentice Hal Inc.

Creswell, J. W. \& P. C. (2011). Designing and Conducting Mixed Methode Research. Los Angeles: Sage Publcation.

Dickson, H., Harvey, J., \& Blackwood, N. (2019). Feedback, feedforward: evaluating the effectiveness of an oral peer review exercise amongst postgraduate students. Assessment and Evaluation in Higher Education, 44(5), 692-704. https://doi.org/10.1080/02602938.2018.1528341

Estaswara, H. (2010). Stakeholder Relation. Jakarta: Universitas Pancasila.

Frizsimmons, J. A., \& Mona, J. F. (2001). Service Management: Operation, Strategy and Information. New York: McGraw Hill Tata McGraw-Hill.

Handayani, R., \& Keban, Y. T. (2004). Analisis Kepuasan Pemakai Terhadap Pelayanan Perpustakaan Nasional Provinsi Daerah Istimewa Yogyakarta $=$ An Analysis on User Satisfaction of the Services Provided by National Library of Yogyakarta Province. Sosiosains, 17(2004).

Kearney, K. S., Naifeh, Z., Hammer, T., \& Cain, A. (2019). "Family" Ties for foster alumni in college: An open systems consideration. Review of Higher Education, 42(2), 793-824. https://doi.org/10.1353/rhe.2019.0015

Kotler, P., \& Keller, K. (2006). Marketing Management: Customer value, customer satisfaction and customer loyalty (12th ed.). Prentice-Hall.

Kotler, P. (2004). Manajemen Pemasaran: Analisis, Perencanaan, implementasi dan Kontrol, Edisi Sebelas. Jakarta: Prenhallindo.

Liu, J., \& Ni, G. (2020). An efficient optimal algorithm for high frequency in wavelet based image reconstruction. Journal of Computational Analysis and Applications, 28(5), 865-878. Retrieved from https: $/ /$ www.scopus.com/inward/record.uri?eid=2s2 $085063649888 \&$ partnerID $=40 \& \mathrm{md} 5=\mathrm{c} 73 \mathrm{a} 91 \mathrm{~d} 7$ 4740899b3e84a7182af5fac8

Mashoufi, M., Ayatollahi, H., \& Khorasani-Zavareh, A. D. (2019). Data Quality Assessment in Emergency Medical Services: What Are the Stakeholders' Perspectives? Perspectives in Health Information Management, 16(Winter). Retrieved from https://www.scopus.com/inward/record.uri?eid=2-s2.085061601036\&partnerID $=40 \& m d 5=$ fcab933b9dd4c303ea4f2334ce7d16b3

Mitrofanova, E. A., Simonova, M. V, \& Tarasenko, V. V. (2020). Potential of the education system in Russia in training staff for the digital economy. Advances in Intelligent Systems and Computing. https://doi.org/10.1007/978-3-030-11367-4_46

Muafi, \& Siswanti, Y. (2007). Anteseden Ekuitas Merek Perguruan Tinggi: SEM dengan Pendekatan Two Step. Manajemen Usahawan Indonesia, 36(3).

Mulyasa, D. (2012). Pendidikan Bermutu Dan Berdaya Saing. Bandung: Remaja Rosdakarya.

Panji, A. (2007). Analisis Faktor-Faktor kualitas Pelayanan Yang Mempengaruhi Kepuasan Mahasiswa Pada Perguruan Tinggi "AUB" Surakarta.

Parasuraman, A., Zeithamel, V. A., \& L.L., B. (1994). Reassesment of Expectation as a Comparasion Standard in Measuring Service Quality: Implication for Further Reaserch. Journal Of Marketing, 58.

Pham, L., Limbu, Y. B., Bui, T. K., Nguyen, H. T., \& Pham, H. T. (2019). Does e-learning service quality influence e-learning student satisfaction and loyalty? Evidence from Vietnam. International Journal of Educational Technology in Higher Education, 16(1). https://doi.org/10.1186/s41239-019-0136-3

Psikologi, F. (2017a). Pedoman Akademik Program Studi Psikologi Islam. Palembang: UIN Raden Fatah Palembang.

Psikologi, F. (2017b). Rencana Strategi Fakultas Psikologi Tahun 2017-2022. Palembang: UIN Raden Fatah Palembang.

Rolbina, E. S., Novikova, E. N., Sharafutdinova, N. S., Martynova, O. V, \& Akhmetshin, R. M. (2020). Analysis and assessment of quality of medical services in conditions of digital transformation. Advances in Intelligent Systems and Computing. https://doi.org/10.1007/978-3-030-11367-4_67

Ruben, B. D. (1999). Toward A Balanced Scorecard for Higher Education: Rethinking the College and University Excellence IndicatorFramwork. Higher Education Forum 99-02 Fall, 1999. New Jersey: 
The Hunter Groupintheir Higher Education White Paper Series.

Sadat, A. M. (2000). Analisis Hubungan Kinerja Jasa Perguruan Tinggi terhadap Kepuasan Mahasiswa: Studi Kasus Universitas Indonesia. Jakarta: Program Pasca Sarjana Ilmu Ekonomi dan Manajemen Universitas Indonesia.

Sugiyono. (2010). Metode Penelitian Kuantitatif, Kualitatif, dan R\&D. Bandung: Alfabeta.

Sukanti. (2009). Analisis Kepuasan Mahasiswa Program Studi Pendidikan Akuntansi FISE UNY. Jurnal Pendidikan Akuntansi Indonesia, 8(1).

Tjiptono, F. (2008). Strategi Pemasaran. Edisi Ketiga. Yogyakarta: Andi.

Tjiptono, F., \& Diana, A. (2003). Total Quality Management. Yogyakarta: Andi.

Vesloguzova, M. V, Petrik, L. S., Salikhov, K. M., \& Bunakov, O. A. (2020). Monitoring as a tool to ensure the quality of services provided in the interaction of service organizations and municipal authorities in economy digitalization. Advances in Intelligent Systems and Computing. https://doi.org/10.1007/978-3-030-11367-4_33

Zhang, R., \& Smith, L. (2019). Bonding and dissonance: Rethinking the Interrelations Among Stakeholders in Heritage Tourism. Tourism Management, 74, 212-223. https://doi.org/10.1016/j.tourman.2019.03.004 